\title{
Faktor yang Berhubungan dengan Penggunaan Metode Kontrasepsi Jangka Panjang (MKJP) di Desa Teupin Raya Peusangan Siblah Krueng Kabupaten Bireuen Tahun 2018
}

\author{
Factors Related To Use Of Long-Term Contraception Method (MKJP) In The \\ Village Of Teupin Raya, Siblah Krueng, Bireuen District, 2018
}

\author{
Misrina*1 Fidiani $^{2}$ \\ ${ }^{1,2}$ Akademi Kebidanan Munawarah, Jalan Sultan Iskandar Muda, No. 18 Kota Juang, Bireuen \\ *Korespondensi Penulis: Misrina517@gmail.com
}

\begin{abstract}
Abstrak
Pemakaian Metode Kontrasepsi JangkaPanjang (MKJP) memiliki banyak keuntungan, baik dilihat dari segi program, maupun dari sisi klien (pemakai). Di samping mempercepat penurunan Total Fertility Rate (TFR), penggunaan kontrasepsi MKJP juga lebih efisien karena dapat dipakai dalam waktu yang lama serta lebih aman dan efektif. Penelitian ini dilakukan untuk melihat faktor-faktor penyebab rendahnya penggunaan metode kontrasepsi jangka panjang (MKJP) di Desa Teupin Raya Peusangan Siblah Krueng Kabupaten Bireuen tahun 2018. Desain penelitian yang digunakan adalah analitik crosssectiona, yang dilakukan pada tanggal 10 Juli 2018. Populasi dalam penelitian ini yaitu seluruh akseptor KB yang ada di Desa Teupin Raya Kecamatan Peusangan Siblah Krueng Kabupaten Bireuen. Tehnik pengambilan sampel yaitu dengan cara total populasi sebanyak 41 orang. Hasil penelitian dilihat dari pengetahuan nilai $\mathrm{p}(0,124)>\mathrm{p}$ value $(0,05)$ berarti Ha ditolak dan Ho diterima, dengan demikian pengetahuan tidak menyebabkan pemakaian MKJP di Desa Teupin Raya Kecamatan Peusangan Siblah Krueng Kabupaten Bireuen. Dilihat dari sosial budaya, menunjukkan nilai $\mathrm{p}(0,001)<\mathrm{p}$ value $(0,05)$ berarti Ha diterima dan Ho ditolak, dengan demikian sosial budaya menyebabkan rendahnya pemakaian MKJP di Desa Teupin Raya Kecamatan Peusangan Siblah Krueng Kabupaten Bireuen. Dilihat dari peran serta tenaga kesehatan, hasil perhitungan menunjukkan nilai $\mathrm{p}(1,000)>\mathrm{p}$ value $(0,05)$ berarti Ha ditolak dan Ho diterima, dengan demikian peran serta tenaga kesehatan tidak menyebabkan rendahnya pemakaian MKJP di Desa Teupin Raya Kecamatan Peusangan Siblah Krueng Kabupaten Bireuen. Diharapkan kepada responden untuk lebih memilih MKJP khususnya bagi akseptor yang tidak mengalami penyakit dalam kontraindikasi MKJP, karena MKJP memiliki efek samping yang rendah dibandingkan kontrasepsi lainnya.
\end{abstract}

Kata Kunci: Pengetahuan, Sosial Budaya, Tenaga kesehatan, MKJP

\begin{abstract}
Use of Long-Term Contraception Methods (MKJP) has many advantages, both in terms of programs, and from the client (user) side. In addition to accelerating the decline in Total Fertility Rate (TFR), MKJP contraceptive use is also more efficient because it can be used for a long time and is safer and more effective. This study was conducted to look at the causes of the low use of long-term contraceptive methods (MKJP) in Teupin Raya Peusangan Village,
\end{abstract}


Siblah Krueng, Bireuen Regency in 2018. The study design used was cross-sectional analytic, which was conducted on July 10, 2018. The population in this study were all family planning acceptors in Teupin Raya Village, Peusangan Siblah Krueng District, Bireuen District. The sampling technique is by means of a total population of 41 people. The results of the study were seen from the knowledge of the value of $p(0.124)>p$ value (0.05) which means Ha was rejected and Ho was accepted, thus knowledge did not cause the use of MKJP in Teupin Raya Village, Peusangan Siblah Krueng District, Bireuen District. Viewed from socio-culture, it shows $p$ value (0.001) <p value (0.05) means that Ha is accepted and Ho is rejected, thus socio-culture causes low use of MKJP in Teupin Raya Village, Peusangan Siblah Krueng District, Bireuen District. Judging from the participation of health workers, the calculation results show the value of $p(1,000)>p$ value $(0.05)$ means Ha is rejected and Ho is accepted, thus the participation of health workers does not cause low use of MKJP in Teupin Raya Village, Peusangan District Siblah Krueng Regency Bireuen. It is expected that respondents to choose MKJP especially for acceptors who do not experience internal disease contraindications MKJP, because MKJP has low side effects compared to other contraceptives.

Keywords: Knowledge, Socio-Culture, Health Workers, MKJP

\section{PENDAHULUAN}

Salah satu upaya pemerintah dalam mengendalikan jumlah penduduk adalah dengan kesehatan reproduksi bagi semua seperti yang tercantum dalam Sustainable Development Goals (SDGs) tujuan 3 yaitu menjamin kehidupan yang sehat dan meningkatkan kesejahteraan penduduk di segala usia dengan indikator meningkatkan Contraceptive Prevalence Rate $(C P R)$. metode $\mathrm{KB}$ hormonal yang paling dominan digunakan oleh peserta $\mathrm{KB}$, sedangkan penggunaan Metode Kontrasepsi Jangka Panjang (MKJP) yang relatif masih rendah di kalangan wanita PUS (Sari, 2017).

Saat ini KB telah dikenal hampir diseluruh dunia, dinegara yang maju KB bukan lagi merupakan suatu program atau gagasan, tetapi telah menjadi falsafah hidup masyarakatnya, sedangkan di negara yang sedang berkembang termasuk Indonesia, KB merupakan program yang pelaksanaannya masih harus terus ditingkatkan (Sibagariang, 2010).

Setiap metode kontrasepsi memiliki keunggulan dan kelemahan. Tidak ada satupunmetode yang sesuai untuk semua pemakai, dan sebagian metode seyogianya tidak digunakan oleh kelompok tertentu karena adanya kontraindikasi. Untuk menyediakan pilihan metode kontrasepsi yang paling tepat bagi para akseptor maka perlu mengetahui tentang efektivitas atau keamanana dari metode -metode kontrasepsi (Brahm, 2016).

Pemakaian Metode Kontrasepsi Jangka Panjang (MKJP) memiliki banyak keuntungan, baik dilihat dari segi program, maupun dari sisi klien (pemakai). Di samping mempercepat 
penurunan Total Fertility Rate (TFR), penggunaan kontrasepsi MKJP juga lebih efisien karena dapat dipakai dalam waktu yang lama serta lebih aman dan efektif. Metode kontrasepsi ini sangat tepat digunakan pada saat kondisi krisis yang dialami oleh sebagian besar masyarakat Indonesia terutama pada masyarakat yang tergolong kurang mampu/miskin (Rahmat, 2017).

Rendahnya minat MKJP dipengaruhi oleh faktor pendidikan dan ekonomi yang rendah, pengetahuan tentang MKJP yang rendah. Pengetahuan MKJP yang rendah karena minimnya informasi yang diperoleh oleh responden. Selain itu, sosial budaya dalam masyarakat juga sangat mempengaruhi penggunaan MKJP, ada persepsi atau budaya setempat yang mengatakan bahwa MKJP bersifat mengakhiri kehamilan, serta mitos efek samping kanker rahim dan mengganggu kualitas hubungan suami istri. Selain itu peran serta tenaga medis juga bisa menunjang tingginya pemakaian metode kontrasepsi jangka panjang (Sari, 2017).

Di seluruh dunia, jumlah perempuan berstatus kawin usia 15-54 tahun yang menggunakan kontrasepsi adalah sebanyak 62\%. Sebagian besar dari mereka menggunakan metode kontrasepsi modern (58\%) seperti suntikan KB (32\%), pil KB (13,6\%), IUD (4\%), susuk KB (3,3\%), dan sterilisasi perempuan (3,2\%). Untuk metode suntik KB paling banyak digunakan oleh perempuan di bawah usia 30 tahun. Sementara pada kelompok perempuan dengan usia yang lebih tua (30-44 tahun) selain suntikan, memakai pil dan metode kontrasepsi jangka panjang seperti IUD, implan, dan sterilisasi perempuan (Risma, 2017).

Badan Kependudukan dan Keluarga Berencana Nasional (BKKBN) memprediksi jumlah penduduk Indonesia berpotensi menjadi terbesar sedunia setelah China dan India jika laju pertumbuhannya tidak bisa ditekan secara signifikan jumlah dan pertumbuhan penduduk Indonesia berdasarkan data sensus penduduk tahun 2010 melebihi angka proyeksi nasional yaitu sebesar 237,6 juta jiwa dengan laju pertumbuhan penduduk 1,49 per tahun. Petumbuhan penduduk yang pesat merupakan akibat dari fertilisasi yang tinggi akan menjadi sumber kemiskinan dan menghambat pertumbuhan ekonomi (Afsari, 2017).

Di Indonesia, laju pertumbuhan penduduk (LPP) dan angka kelahiran total (total fertility rate/TFR) menjadi bagian dari sasaran/program strategis Badan Kependudukan dan Keluarga Berencana Nasional (BKKBN) dalam Rencana Pembangunan Jangka Menengah Nasional (RPJMN) 2015-2019. Pencapaian peserta KB aktif (PA) nasional sampai dengan Oktober 2017 mencapai 35.585.999 peserta dari sekitar 47.785.810 pasangan usia subur (PUS). Hingga akhir tahun ini ditargetkan, peserta KB bisa mencapai 37.556 .901 orang di seluruh Indonesia (Media Indonesia, 2017). 
Masalah utama yang dihadapi Indonesia di bidang kependudukan adalah pertumbuhan penduduk yang masih tinggi. Upaya mewujudkan keluarga berkualitas, sasaran utamanya adalah terkendalinya pertumbuhan penduduk dan meningkatnya keluarga kecil berkualitas ditandai meningkatnya penggunaan metode kontrasepsi yang rasional, efektif dan efesien yakni MKJP (Hidayat, 2017).

Banyak sisi yang mempengaruhi penggunaan metode kontrasepsi jangka panjang seperti pengetahuan PUS, pendidikan PUS, jumlah paritas, usia, dukungan suami, kenyamanan seksual, kepercayaan, budaya, dan pemberian informasi dari pihak tenaga kesehatan (Danila, 2015).

Di Indonesia, prevalensi pemakaian kontrasepsi menurut beberapa survey dan pendataan keluarga SRPJMN tahun 2017 menunjukkan bahwa persentase KB aktif MKJP sebanyak 21,5\%, kontrasepsi modern 57,6\%, kebutuhan KB yang tidak terpenuhi 17,5\%. Jumlah cakupan MOW 3,0\%, MOP 0,1 \%, IUD 3,6\%, susuk 5,7\%, suntik 31,7\%, pil 12,3\%, kondom 1,2\%, MAL 0,1\%, tradisional 2,1\% (Listyawardani, 2017).

Di Provinsi Aceh, prevalensi alat kontrasepsi modern atau CPR menurut cara atau alat KB dan prevalensi KB berdasarkan laporan RPJMN tahun 2017, untuk provinsi Aceh tercatat cakupannya sebanyak 51,6\%, kebutuhan $\mathrm{KB}$ yang tidak terpenuhi (unmet need) yaitu sebanyak 22,8\%, (Listyawardani, 2017).

Di Kabupaten Bireuen, jumlah akseptor KB sebanyak 62.912 akseptor. Dengan jumlah akseptor MKJP sebanyak 3.916 akseptor (6,2\%), non MKJP sebanyak 58.996 akseptor (92,91\%). Jumlah akseptor IUD sebanyak 1.799 (2,9\%), MOP sebanyak 2 (0,0\%), MOW 467 $(0,7 \%)$, dan implant 1.648 (2,6\%). Dari 18 kecamatan yang ada di kabupaten Bireuen, kecamatan Peusangan Siblah Krueng merupakan kecamatan dengan jumlah akseptor MKJP paling rendah yaitu sebanyak 45 akseptor (Dinas Kesehatan Kabupaten Bireuen, 2017).

Di kecamatan Peusangan Siblah Krueng, jumlah akseptor KB MKJP dan non MKJP sebanyak 1.610, dengan jumlah akseptor KB MKJP hanya 45 orang. Jumlah ini sangat sedikit bila dibandingkan dengan jumlah non MKJP yaitu sebanyak 1.565 jiwa (Profil KB Puskesmas Peusangan Siblah Krueng, 2017).

Dari hasil survey awal yang dilakukan di Puskesmas Peusangan Siblah Krueng, jumlah akseptor KB IUD sebanyak 55 orang, KB implant sebanyak 4 orang, KB MOW sebanyak 31 orang, MOP 0 orang, jumlah ini masih sangat rendah jika dibandingkan dengan jumlah pengguna KB sebanyak 1.195. Desa dengan persentase pemakaian MKJP terendah yaitu Desa Teupin Raya sebanyak 6 akseptor dengan 5 orang peserta lama dan 1 orang peserta baru. 
Berdasarkan data diatas, maka peneliti tertarik untuk meneliti tentang "Faktor yang berhubungan dengan penggunaan metode kontrasepsi jangka panjang (MKJP) di Desa Teupin Raya Peusangan Siblah Krueng Kabupaten Bireuen tahun 2018.

Tujuan penelitian ini untuk mengetahui faktor-faktor yang berhubungan dengan penggunaan metode kontrasepsi jangka panjang (MKJP) di Desa Teupin Raya Peusangan Siblah Krueng Kabupaten Bireuen tahun 2018.

Penelitian ini diharapkan Sebagai bahan informasi dan masukan kepada responden agar menggunakan MKJP sehingga penggunaannya juga lebih meningkat.

\section{METODE PENELITIAN}

Desain penelitian yang digunakan adalah penelitian analitik dengan pendekatan cross sectional, yaitu penelitian yang dilakukan dengan tujuan utama untuk menjawab permasalahan yang sedang dihadapi pada situasi seseorang untuk melihat factor yang berhubungan dengan penggunaan metode kontrasepsi jangka panjang (MKJP) di Desa Teupin Raya Peusangan Siblah Krueng Kabupaten Bireuen tahun 2018.

Penelitian ini telah dilakukan di Desa Teupin Raya Peusangan Siblah Krueng Kabupaten Bireuen. Penelitian ini telah dilaksanakan pada tanggal 10 Juli 2018. Populasi dalam penelitian ini adalah seluruh akseptor KB yang ada di Desa Teupin Raya Peusangan Siblah Krueng Kabupaten Bireuen tahun 2018 sebanyak 41 orang. Pengambilan sampel diambil secara total sampling yaitu seluruh akseptor KB yang ada di Desa Teupin Raya Peusangan Siblah Krueng Kabupaten Bireuen tahun 2018 sebanyak 41 orang.

Jenis data yang digunakan dalam penelitian ini adalah data primer dan data sekunder. Metode pengelohan data collecting, checking, coding, entering dan processing. Analisis data yang digunakan adalah analisis univariat dan analisis bivariat dengan uji chi-square.

\section{HASIL DAN PEMBAHASAN}

Tabel 1. dapat dilihat tabulasi silang terhadap pengetahuan, dari 41 responden mayoritas yang tidak menggunakan MKJP yaitu ibu yang memiliki pengetahuan cukup tentang MKJP yaitu sebanyak 15 responden (37\%).

Dari hasil uji chi square dengan tingkat kepercayaan 95\% $(\alpha=0,05)$ hasil perhitungan menunjukkan nilai $\mathrm{p}(0,124)>\mathrm{p}$ value $(0,05)$ berarti Ha ditolak dan Ho diterima, dengan 
demikian pengetahuan tidak menyebabkan rendahnya pemakaian MKJP di Desa Teupin Raya Kecamatan Peusangan Siblah Krueng Kabupaten Bireuen.

Dari tabulasi silang terhadap sosial budaya dari 41 responden mayoritas responden yang tidak menggunakan MKJP memiliki sosial budaya yang negatif tentang penggunaan MKJP yaitu sebanyak 31 responden (75\%). Dari hasil uji chi square dengan tingkat kepercayaan $95 \%(\alpha=0,05)$ hasil perhitungan menunjukkan nilai $\mathrm{p}(0,001)<\mathrm{p}$ value $(0,05)$ berarti Ha diterima dan Ho ditolak, dengan demikian sosial budaya menyebabkan rendahnya pemakaian MKJP di Desa Teupin Raya Kecamatan Peusangan Siblah Krueng Kabupaten Bireuen.

Dari tabulasi silang terhadap peran tenaga kesehatan dari 41 responden mayoritas yang tidak menggunakan MKJP memiliki peran serta yang aktif tentang MKJP yaitu sebanyak 33 responden (80\%). Dari hasil uji chi square dengan tingkat kepercayaan 95\% $(\alpha=0,05)$ hasil perhitungan menunjukkan nilai $\mathrm{p}(1,000)>\mathrm{p}$ value $(0,05)$ berarti ha ditolak dan ho diterima, dengan demikian tidak ada hubungan peran serta tenaga kesehatan dengan penggunaan MKJP.

Tabel 1. Tabulasi Silang Faktor yang Berhubungan Dengan Penggunaan Metode Kontrasepsi Jangka Panjang (MKJP) di Desa Teupin Raya Peusangan Siblah Krueng Kabupaten Bireuen tahun 2018

\begin{tabular}{|c|c|c|c|c|c|c|c|}
\hline \multirow{3}{*}{ Variabel } & \multicolumn{4}{|c|}{ Penggunaan MKJP } & \multirow{2}{*}{\multicolumn{2}{|c|}{ Jumlah }} & \multirow{3}{*}{ Asymp.Sig } \\
\hline & \multicolumn{2}{|c|}{ Ya } & \multicolumn{2}{|c|}{ Tidak } & & & \\
\hline & $\mathbf{f}$ & $\%$ & $\mathbf{f}$ & $\%$ & $\mathbf{F}$ & $\%$ & \\
\hline Pengetahuan & & & & & & & \multirow{4}{*}{0,124} \\
\hline Baik & 3 & 7 & 7 & 17 & 10 & 24 & \\
\hline Cukup & 3 & 7 & 15 & 37 & 18 & 44 & \\
\hline Kurang & 0 & 0 & 13 & 32 & 13 & 32 & \\
\hline \multicolumn{8}{|l|}{ Sosial Budaya } \\
\hline Positif & 5 & 12 & 4 & 10 & 9 & 22 & \\
\hline Negatif & 1 & 3 & 31 & 75 & 32 & 78 & \\
\hline \multicolumn{8}{|l|}{ Sikap } \\
\hline Positif & 23 & 50,0 & 23 & 50,0 & 46 & 100 & \\
\hline Negatif & 2 & 5,4 & 35 & 94,6 & 37 & 100 & 0,000 \\
\hline \multicolumn{8}{|c|}{ Peran Tenaga Kesehatan } \\
\hline Aktif & 6 & 15 & 33 & 80 & 39 & 95 & \\
\hline Tidak Aktif & 0 & 0 & 2 & 5 & 2 & 5 & 1,000 \\
\hline
\end{tabular}




\section{Pembahasan}

1. Faktor Pengetahuan terhadap rendahnya penggunaan MKJP

Dari hasil uji chi square dengan tingkat kepercayaan 95\% $(\alpha=0,05)$ hasil perhitungan menunjukkan nilai $\mathrm{p}(0,124)>\mathrm{p}$ value $(0,05)$ berarti Ha ditolak dan Ho diterima, dengan demikian pengetahuan tidak menyebabkan rendahnya pemakaian MKJP di Desa Teupin Raya Kecamatan Peusangan Siblah Krueng Kabupaten Bireuen.

Penelian Heryaryanti (2014) faktor-faktor yang berhubungan dengan penggunaan kontrasepsi pada wanita kawin usia dini mengatakan bahwa pengetahuan tidak memiliki hubungan yang bermakna dengan penggunaan alat kontrasepsi pada wanita kawin usia dini berdasarkan uji statistik nilai $\mathrm{P}=0,676$. Pendapat ini diperkuat lagi dalam penelitian yang dilakukan Nurfaedah dkk (2013) dalam penelitiannya yang mengatakan bahwa berdasarkan hasil analisis dengan uji statistik menunjukkan nilai $\mathrm{P}=0,436$ yang artinya tidak ada hubungan yang signifikan antara tingkat pengetahuan denga penggunaan alat kontrasepsi (Dikutip oleh Afsari, 2017).

Dari hasil penelitian tersebut diatas, tidak ada hubungan pengetahuan dengan pemilihan kontrasepsi, penelitian tersebut menguatkan hasil penelitian dalam penelitian ini.

Sesuai dengan pendapat BKKBN (2005) yaitu pengetahuan terhadap alat kontrasepsi pada masyarakat sudah tidak asing lagi terutama pada ibu atau akseptor mengenai alat kontrasepsi KB tersebut sudah tidak tahu lagi dibicarakan namun pengetahuan yang sudah ada pada masyarakat hanya sebatas tahu, belum tentu sesuai dengan perilaku yang diharapkan. Jika mereka merasa perlu lebih tahu mengenai alat kontrasepsi maka mereka akan pergi ke tempat pelayanan kesehatan (Dikutip dari Ayunda, 2013).

Asumsi peneliti, pengetahuan akseptor masih dalam kategori cukup karena mayoritas responden memiliki pendidikan rata-rata menengah, sehingga informasi yang diperoleh masih belum maksimal tentang metode kontrasepsi jangka panjang. Selain itu responden memiliki umur antara 20 sampai 35 tahun, sehingga minat untuk pemakaian MKJP masih rendah, karena amereka masih merencanakan kehamilan dengan usia yang masih produktif.

\section{Faktor Sosial Budaya terhadap rendahnya penggunaan MKJP}

Berdasarkan uji silang diatas, mayoritas responden yang tidak menggunakan MKJP memiliki sosial budaya yang negatif tentang penggunaan MKJP yaitu sebanyak 31 responden (75\%). Dari hasil uji chi square dengan tingkat kepercayaan $95 \%(\alpha=0,05)$ 
hasil perhitungan menunjukkan nilai $\mathrm{p}(0,001)<\mathrm{p}$ value $(0,05)$ berarti Ha diterima dan Ho ditolak, dengan demikian sosial budaya dapat menyebabkan rendahnya pemakaian MKJP di Desa Teupin Raya Kecamatan Peusangan Siblah Krueng Kabupaten Bireuen.

Penelitian terdahulu pernah diteliti oleh Assalis pada tahun 2015 dengan judul "Hubungan Sosial Budaya Dengan Pemilihan Metode Kontrasepsiasil penelitian sebagian besar responden memiliki sosial budaya yang tidak mendukung yaitu sebanyak 60 responden $(51,7 \%)$, sebagian besar responden menggunakan metode kontrasepsi yaitu sebanyak 67 responden $(57,8 \%)$. Ada hubungan sosial budaya dengan pemilihan metode kontrasepsi di Wilayah Kerja Puskesmas Branti Natar Lampung Selatan tahun 2015 ( $p$ value $=0,002$ dan $\mathrm{OR}=3,574$ ). Kesamaan penelitian Assalis (2015) dengan penelitian ini yaitu terletak pada hasil penelitian yang menyatakan sosial budaya menyebabkan rendahnya pemakaian MKJP. Perbedaannya yaitu terletak pada pada jumlah sampel, tempa penelitian, waktu penelitian.

Menurut Pendit (2005), sejumlah faktor budaya dapat mempengaruhi klien dalam memilih metode kontrasepsi. Faktor-faktor ini meliputi salah pengertian dalam masyarakat mengenai berbagai metode, kepercayaan religius serta budaya, tingkat pendidikan, persepsi mengenai risiko kehamilan, dan status wanita. Penyedia layanan harus menyadari bagaimana faktor-faktor tersebut mempengaruhi pemilihan metode di daerah mereka dan harus memantau perubahan-perubahan yang mungkin mempengaruhi pemilihan metode (Dikutip dalam Assalis, 2015).

Asumsi peneliti, terdapat pengaruh besar antara sosial budaya dengan penggunaan Metode Kontrasepsi Jangka Panjang (MKJP), karena di desa ini masih melekat sosial budaya yang menurut mereka tidak memperbolehkan menggunakan Metode Kontrasepsi Jangka Panjang (MKJP) seperti AKDR, implant, MOP dan MOW dengan alasan mereka malu mengangkang ketika pemasangan IUD, sementara pada pemasangan implant, mereka beranggapan tindakan tersebut merugikan pemakai, karena harus dibedah.

3. Faktor tenaga kesehatan terhadap rendahnya penggunaan MKJP

Berdasarkan uji silang diatas, yang tidak menggunakan MKJP memiliki peran serta yang aktif tentang MKJP yaitu sebanyak 33 responden (80\%).

Dari hasil uji chi square dengan tingkat kepercayaan 95\% $(\alpha=0,05)$ hasil perhitungan menunjukkan nilai $\mathrm{p}(1,000)>\mathrm{p}$ value $(0,05)$ berarti Ha ditolak dan Ho diterima, dengan demikian peran serta tenaga kesehatan tidak menyebabkan rendahnya 
pemakaian MKJP di Desa Teupin Raya Kecamatan Peusangan Siblah Krueng Kabupaten Bireuen.

Penelitian terdahulu pernah diteliti oleh Pitriani pada tahun 2016 dengan judul Hubungan Pendidikan, Pengetahuan dan Peran Tenaga Kesehatan dengan Penggunaan Kontrasepsi Intra Uterine Device (IUD) di Wilayah Kerja Puskesmas Rawat Inap Muara Fajar Pekanbaru", hasilnya Ada hubungan antara peran tenaga kesehatan dengan penggunaan kontrasepsi IUD ( $p$ value $=0,034)$, dengan OR= 8,329 (95\%CI: 1,016-68,254) artinya ibu yang kurang mendapatkan peran tenaga kesehatan lebih beresiko 8 kali tidak menggunakan IUD dari pada ibu yang mendapatkan peran tenaga kesehatan. Perbedaan penelitian Pitriani (2015) dengan penelitian ini yaitu hasil penelitian tidak menunjukkan hubungan atau penyebab. Perbedaannya terletak pada variabel penelitian dependen, pada penelitian ini variabel dependen yaitu pemakaian MKJP namun pada penelitian Pitriani variabel dependen penggunaan KB IUD. Perbedaan lain terletak pada waktu, tempat dan jumlah sampel penelitian.

Asumsi peneliti, peran serta tenaga medis dalam kategori aktif, namun pemakaian Metode Kontrasepsi Jangka Panjang (MKJP) masih sedikit dikarenakan petugas medis hanya menjelaskan dan memperkenalkan Metode Kontrasepsi Jangka Panjang (MKJP). Namun untuk keputusan pemilihan alat KB tetap ditangan akseptor sendiri. Namun demikian, meskipun tenaga kesehatan aktif dalam mempromosikan, budaya setempat sangat melatar belakangi susksesnya pemakaian Metode Kontrasepsi Jangka Panjang (MKJP) atau tidak.

Tenaga kesehatan adalah setiap orang yang mengabdikan diri dalam bidang kesehatan serta memiliki pengetahuan dan/atau keterampilan melalui pendidikan di bidang kesehatan untuk jenis tertentu memerlukan kewenangan untuk melakukan upaya kesehatan. Tenaga kesehatan dalam hal ini berperan sebagai pemberi pelayanan KB dengan melakukan penanganan sesuai dengan efek samping yang muncul dari akseptor. Peran yang baik dalam menangani efek samping berdampak positif pada teratasinya keluhan efek samping yang dirasakan ibu, sebaliknya peran yang kurang dari tenaga kesehatan berdampak pada efek samping yang tidak tertangani dan masih dialami oleh ibu. Selain itu kemungkinan dropout dalam menjadi akseptor KB sangat mungkin terjadi akibat dari efek samping yang dialami oleh ibu. Peran serta yang baik dari tenaga kesehatan setempat dilakukan melalui kegiatan promotif yaitu melalui konseling, penyuluhan kelas ibu, maupun pasangan usia subur di pelayanan kesehatan. Tenaga kesehatan setempat 
memiliki peran yang baik karena mampu memberikan perubahan hasil yang positif bagi lingkungan setempat, hal ini dapat diperkuat dari adanya data dukung penunjang seperti data pencatatan, serta perubahan yang dapat dilihat secara langsung.

\section{KESIMPULAN}

Kesimpulan peneliti ini ada pengaruh antara sosial budaya terhadap rendahnya penggunaan MKJP di Desa Teupin Raya Kecamatan Peusangan Kabupaten Bireuen serta tidak pengaruh pengetahuan, dan peran tenaga kesehatan, terhadap rendahnya penggunaan MKJP di Desa Teupin Raya Kecamatan Peusangan Kabupaten Bireuen Tahun 2018

\section{SARAN}

Disarankan kepada masyarakat Desa Teupin Raya untuk dapat meningkatkat pemahaman terhadap penggunaan MKJP sehingga mau diterima oleh sosial budaya setempat dalam rangka upaya yang signifikan, guna meningkatkan cakupan penggunaan metode kontrasepsi Jangka Panjang (MKJP).

\section{DAFTAR PUSTAKA}

Afsari (2017). Faktor Yang Mempengaruhi Akseptor KB Dalam Memilih Kontrasepsi Di Puskesmas Jumpandang Baru Makassar" Universitas Islam Alaudin Makasar. www.jurnalkesehatan.com. Diakses Oleh Misrina tanggal 20 Mei 2018.

Assalis (2015). Hubungan Sosial Budaya Dengan Pemilihan Metode Kontrasepsi. Universitas Malahayati Lampung. Diakses oleh Misrina tanggal 27 Juli 2018

Ayunda (2013). Faktor-Faktor Yang Berhubungan Dengan Pemilihan Metode Kontrasepsi Oleh PUS Di Desa Peunyerat Kecamatan Banda Raya Banda Aceh. Program Studi Diploma IV Kebidanan STIKes U’Budiyah Banda Aceh. www. Jurnalkti.com. Diakses oleh Misrina pada tanggal 28 Juli 2018.

BKKBN, (2011). Buku Panduan Praktis Pelayana Kontrasepsi. Direktorat Kesehatan Reproduksi. Jakarta.

Brahm (2016). Ragam Metode Kontrasepsi. Jakarta: EGC.

Danila (2015). Konsep Keluarga Berencana. http//e-joernalkesehatan.pdf.com. Diakses oleh Misrina pada tanggal 21 Juli 2018 at 08.50

Dinkes Aceh, 2017. Profil Kesehatan Provinsi Aceh, [online], www. Dinkes.aceh.go.id, Diakses oleh Misrina pada tanggal 23 Juli 2018.

Everett (2012). Buku Saku Kontrasepsi \& Kesehatan Seksual Reproduksi. Jakarta: EGC.

Glasier (2014). Keluarga Berencana \& Kesehatan Reproduksi. Jakarta: EGC. 
Iman. M (2015). Panduan Penyusunan Karya Tulis Ilmiah Bidan Kesehatan. Cita Pusaka: Medan.

— (2014). Pengukuran Variabel dengan SPSS. Cita Pusaka: Medan.

Listyawardani (2017). Pelayanan KB dan Kesehatan Reproduksi http//ejoernal.bkkbnswop.pdf.com. Diakses oleh Misrina pada tanggal 24 Juli 2018, at 08.40

Machfoedz. (2009). Metodologi Penelitian Kualitatif dan Kuantitatif, Keperawatan, Kedokteran, Fitramaya: Yogyakarta.

Media Indonesia (2017). Peserta KB terus ditingkatkan. Nusantarabkkbn. http.//mediaindonesianews.com.

Meilani, dkk, 2012. Pelayanan Keluarga Berencana. Yogjakarta: Fitramaya.

Notoadmodjo. (2010), Promosi dan Perilaku Kesehatan, Jakarta: Rineka Cipta.

Pitriani (2015). Hubungan Pendidikan, Pengetahuan dan Peran Tenaga Kesehatan

dengan Penggunaan Kontrasepsi Intra Uterine Device (IUD) di Wilayah Kerja Puskesmas Rawat Inap Muara Fajar Pekanbaru. www. jurnalkesehatankomunitas.com.

Rahmat (2017). Perilaku Akseptor Dalam Memilih Metode Kontrasepsi Jangka Panjang (Mkjp) Di Poskesdes Anuta Singgani Kecamatan Mantikulore Kota Palu. Program Studi Kesehatan Masyarakat, Universitas Tadulako http//e-joernal.UT.pdf.com. Diakses oleh Misrina pada tanggal 24 Juli 2018.

Risma (2017). Kependudukan dunia, KB dan radikalisme. http.//geolive.com//pdf. Diakses oleh Misrina pada tanggal 25 Juli 2018 at 10.00 am

Sari (2017). Faktor-Faktor Yang Mempengaruhi Rendahnya Pemilihan Alat Kontrasepsi MKJP Pada PUS Di Puskesmas Tembilahan Hulu. www. jurnalpublikasi.com. Diakses oleh Misrina pada tanggal 24 Juli 2018.

Sibagariang, dkk (2010. Kesehatan Reproduksi Wanita. Jakarta: Trans Info Media.

Sumargo (2009). Keluarga Berencana dan Kontrasepsi. Jakarta: Sinar Harapan.

Sutiawan (2014). Konsep KB MKJP. http//konsepmkjp//pdf//.com. Diakses oleh Misrina. Pada tanggal 16 Juli 2018 at 10.00 am 